\begin{tabular}{|c|c|}
\hline $\begin{array}{l}\text { Australian Journal of } \\
\text { Crop Science }\end{array}$ & AJCS \\
\hline $\begin{array}{l}\text { CS 10(8):1144-1150 (2016) } \\
\text { JI: To be issued soon }\end{array}$ & ISSN:1835-2707 \\
\hline
\end{tabular}

\title{
Effect of different conductor tubes on the longitudinal distribution of soybean seeds
}

\author{
Dauto Pivetta Carpes* ${ }^{1}$, Airton Dos Santos Alonço ${ }^{1}$, Tiago Rodrigo Francetto ${ }^{1}$, Cristian Josue \\ Franck $^{1}$, Mateus Potrich Bellé ${ }^{2}$, Otávio Dias da Costa Machado ${ }^{3}$
}

${ }^{1}$ Federal University of Santa Maria, Postgrad Program in Agricultural Engineering, City Santa Maria, State of

Rio Grande do Sul, Brazil

${ }^{2}$ Federal Institute of Santa Catarina, São Carlos City, State of Santa Catarina, Brazil

${ }^{3}$ Federal Institute of Rio Grande do Sul, Bento Gonçalves City, State of Rio Grande do Sul, Brazil

*Corresponding author: dautocarpes@gmail.com

\begin{abstract}
Some crops have great sensitivity to the population variation and also to the spacing arrangement between seeds in the seeding row. This way, the longitudinal distribution of seeds by seed metering mechanisms must be highly accurate. The objective of this study was to evaluate the effect of the seed conductor tube type, combined with pneumatic and horizontal disc meter mechanisms, varying the seeding density rate. The experiment was conducted in a laboratory using a seed meter test bench. Treatments consisted of a combination among two seed meters, six conductor tubes and four peripheral speeds for the discs, corresponding to the densities of $250,300,350$ and 400 thousand soybean seeds $\mathrm{ha}^{-1}$, organized in a three-factor scheme with four repetitions. When increasing seeding density rate with the same ground speed, there was a reduction in the acceptable spacing percentage, however, conductor tubes with a parabolic profile, angle close to 30 degrees showed the best performance in relation to longitudinal seed distribution, regardless of the type of seed meter used.
\end{abstract}

Keywords: Agricultural mechanization; agricultural engineering; seed meter; precision agriculture; seeder-fertilizer. Abbreviations: ha_hectare; ISO_International Standart Organization; ABNT_Brazilian Association of Technical Standards; HD_Horizontal Disc; P_Pneumatic; rpm_Rotations per minute.

\section{Introduction}

Crop yield is closely related to the quality of the seeding operation. Therefore, one of the main factors involved is the establishment of a stand with plants evenly arranged in the rows, providing a better directly influenced by the adopted spacing between plants (Heiffig et al. 2006). These authors claim that some cultivars show high plasticity and adaptation, in such way that the leaf area index increases with the increasing of plant density.

Regarding the machines that perform the seeding of these crops, an important factor to be observed is the ground speed, which, according to Oliveira et al. (2000), significantly influences on the number of seeds per hectare, the final plant population, the seeder depth, as well as the seeds longitudinal distribution. Regarding the conductive tubes, those with longer lengths provide longer trajectories, increasing the rebounds, affecting the seeds distribution. Silva et al. (2000) warn that when moving under the soil seeds are subject to vibrations inside the conductor tube caused by the movement of the seeder, causing changes in the seeds falling time, and therefore non-uniform spacing on the seeding line. The ground speed of the seeding, the authors say, may be a factor that causes the rebounds of seeds in the conductor tube.

Mialhe (2012) states that the vertical conductor, conducting the seeds by the action of gravity can be highly damaging in precision sowing by causing the rebound effect of the seeds inside. Jasper et al. (2006), say the parabolic profile tubes lead the seeds to the furrow more smoothly, reducing this effect. Regarding seed trajectory, Tourino et al. (1996) states that the variation of the peripheral speed of the seed meter disks directly influences the trajectory the seed will follow after its release. It still has its contribution increased by the format, the length and the inclination of the conductor tube. This way, the objective of the study was to evaluate seed conductive tubes of different diameters, their placement in the machine, height from the ground and discharge bend, when combined with two seed meter systems, horizontal honeycomb disk and vertical pneumatic disk, at different seeding densities and peripheral speeds of the meter disk, based on the longitudinal distribution of soybean seeds.

\section{Results and Discussion}

The ANOVA results of the factors precision; acceptable, multiple and flawed spacing; as well as their interactions are detailed in Table 4. The CV values for flawed spacing from F1, F2 and F3 factors are slightly above the proposed by Coelho (1996), that is, values of $30 \%$ for the evaluation of pneumatic seed meters. As for the horizontal disc meter, values are still in the acceptable range, which is a maximum of $50 \%$. This fact can be explained by the high variability found in the averages of spacing generated by small and large seed deposition flaws, an observation that is shared by Kachman and Smith (1995). 
Table 1. Dimensional characteristics of soybeans used in the tests.

\begin{tabular}{lll}
\hline Variable & Average & SD $^{[a]}$ \\
\hline Width $(\mathrm{mm})$ & 7.37 & 0.35 \\
Thickness $(\mathrm{mm})$ & 5.01 & 0.22 \\
Length $(\mathrm{mm})$ & 6.49 & 0.20 \\
1000 seeds mass $(\mathrm{g})$ & 164.30 & 3.18 \\
Sphericity \% & 95.68 & 3.53 \\
\hline
\end{tabular}

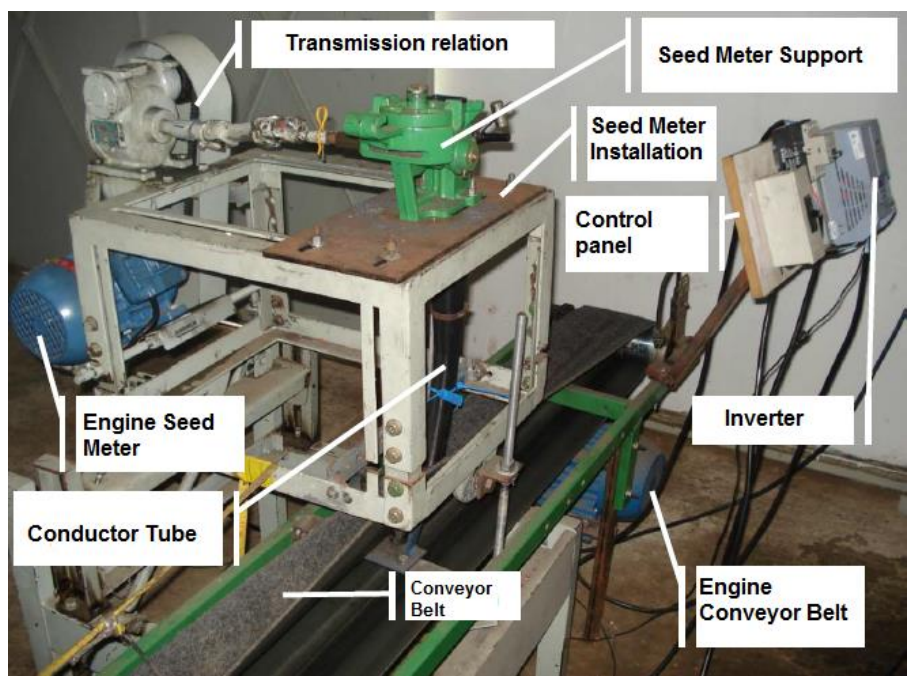

Fig 1. Seed meter test bench and Conveyor belt spacing between seeds evaluation (BEDOSA).

Table 2. Shows the settings used in the horizontal and pneumatic disc meters.

\begin{tabular}{|c|c|c|c|c|}
\hline \multicolumn{5}{|c|}{ Vertical pneumatic disc } \\
\hline Seed $\mathrm{m}^{-1}$ & Seeds ha ${ }^{-1}$ & Rotation (rpm) & $\begin{array}{l}\mathrm{PS}^{[\mathrm{a}]} \\
\left(\mathrm{m} \mathrm{s}^{-1}\right)\end{array}$ & $\begin{array}{l}\mathrm{CBS}^{[\mathrm{b}]} \\
\left(\mathrm{m} \mathrm{s}^{-1}\right)\end{array}$ \\
\hline 11.25 & 250.000 & 14.06 & 0.125 & 1.67 \\
\hline 13.50 & 300.000 & 16.87 & 0.151 & 1.67 \\
\hline 15.75 & 350.000 & 19.68 & 0.176 & 1.67 \\
\hline 18.00 & 400.000 & 22.50 & 0.201 & 1.67 \\
\hline \multicolumn{5}{|c|}{ Horizontal Disc } \\
\hline Seed $\mathrm{m}^{-1}$ & Seeds ha ${ }^{-1}$ & Rotation (rpm) & $\begin{array}{l}\text { PS } \\
\left(\mathrm{m} \mathrm{s}^{-1}\right)\end{array}$ & $\begin{array}{l}\text { CBS } \\
\left(\mathrm{m} \mathrm{s}^{-1}\right)\end{array}$ \\
\hline 11.25 & 250.000 & 12.50 & 0.130 & 1.67 \\
\hline 13.50 & 300.000 & 15.00 & 0.157 & 1.67 \\
\hline 15.75 & 350.000 & 17.50 & 0.183 & 1.67 \\
\hline 18.00 & 400.000 & 20.00 & 0.209 & 1.67 \\
\hline
\end{tabular}

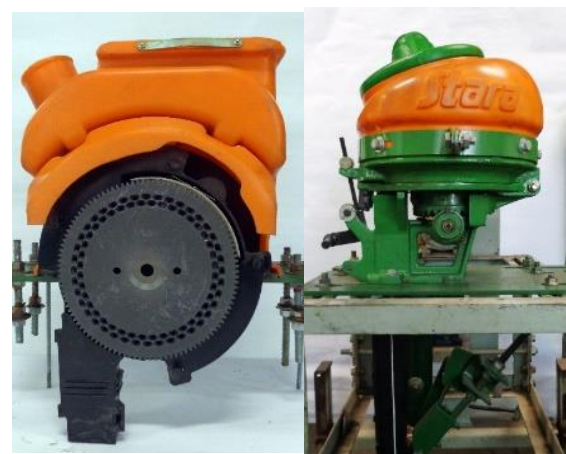

Fig 2. Pneumatic seed meter and horizontal disc meter. 


\section{Precision seed spacing}

According to the data shown in Table 5, which presents the interaction between the conductor tube and the seed meter, tube 4 (T4) obtained the worst average precision values, the practical limit set by Kachman and Smith (1995) being of 29 $\%$. The reason for the reduction in precision, when compared to the others, can be associated with its format, as well as that of the seed. This is consistent with the findings by Futral and Allen (1951) where, due to the seed sphericity, upon entering in contact with the cylindrical conductors, the seeds acquire a spiraling motion, scattering their fall and causing greater errors in deposition.

On average, the horizontal disc meter (HD) obtained the worst precision in relation to the pneumatic seed meter $(\mathrm{P})$. This fact is due to the trajectory the seed takes when released by the disc meter, where the HD deposits the seed transversally to the falling direction, disfavoring the descent to the ground, while the P deposits in the same direction of the fall, favoring correct seed trajectory. The T3 and T6 tubes had the best precision when used with the P meter. The T1, T2, T3, T5 and T6 tubes had better precision than the T4 tube when used with the HD meter, but the precision was not as good as when used with the P meter.

\section{Acceptable spacing between seeds}

Table 6 shows the result of the interaction between the seed meter and density factors for the acceptable spacing variable. When the HD was used, the largest different in the acceptable spacing percentages was 5.05 percentage points. It can be observed that with the increase of seeding density rate, resulting from the peripheral speed increase of the meter disc, the acceptable spacing of the $\mathrm{P}$ was reduced.

This fact can be explained by the form of the seed release. In increasing the seeding density and, consequently the peripheral speed of the $\mathrm{P}$ disc meter, the seeds acquire a higher drop rate, increasing the occurrence of rebounds inside the conductor and also causing the effect of jumps or rolling in the bottom of the planting furrow, process reported by Bernacki et al. (1984). With the seeding density increase, the two mechanisms used obtained similar results, in agreement with the findings by Dias et al. (2009), which found no significant differences in seeding density with the increase of ground speed. Fig 4 shows the regression equations between the acceptable spacing averages and seeding density for HD and $\mathrm{P}$ seed meters, combined with different conductor tubes.

With the increase in seeding density, there was a reduction of acceptable spacing for most tube conductors. When combined with the $\mathrm{P}$, the conductors number 2, 4 and 5 in Fig $\mathrm{B}, \mathrm{D}$ and $\mathrm{E}$, respectively, did not show a significant reduction in the performance. However, they presented a low percentage of acceptable spacing, corroborating the results obtained by Reis et al. (2007), who found no linear response in the regularity of longitudinal seed distribution.

The best results were observed in the P seed meter with T3 and $\mathrm{T} 6$ tubes that have a seed exit angle close to $30^{\circ}$. This observation is shared by Wanjura and Hudspeth (1968), who cite this exit angle as the one that enables better seed conductor tube performance. For these conductors (Figure C and F), the acceptable spacing percentages were approximately equivalent at higher densities. In addition, because they visually show an inner surface with less surface roughness, these two conductors provided less grip on their inner walls, meaning that there was less turbulence in the seed trajectory, and consequently less loss in the quality of longitudinal distribution. This observation is shared by Kocher et al. (2011) who noted that for both round and flat seed, seed spacing uniformity was poorer for conductor tubes with worn inside surfaces when compared to new tubes.

\section{Multiple spacing between seeds}

Table 7 shows multiple spacing averages for the interaction between seed meter and conductor tube factors. It was observed that, when used with the HD, the T2, T4 and T5 tubes did not significantly differ from each other with the highest multiple spacing averages. These three tubes also had the highest multiple spacing averages when used with the P. The T2 tube provided the highest multiple spacing average among the tubes when used with the HD, which may be due to the small dimensions at the seeds outlet end, causing a greater contact with the conductor walls, and provoking a higher occurrence of seed rebounds. In this manner, a delay in the seed drop may be caused, meaning that the subsequent seed deployed would reach it, corroborating the conclusions of Bainer (1963).

The T4 conductor also had an increase of multiple spacing average when used with the $\mathrm{P}$. The possible cause here may have been the impact angle of the seed on entering the conductor, combined with the cylindrical shape which can increase the occurrence of seed rebounding and scattering through the conductor, in agreement with the findings of Futral \& Allen (1951).

The T3 and T6 conductors had the lowest multiple spacing average with both the $\mathrm{P}$ and HD seed meters. This fact may be related to the curvature of the conductor tube, corroborating findings by Wanjura \& Hudspeth (1968). The T3 and T6 conductors both had lower multiple spacing averages (better seed spacing uniformity) with the $\mathrm{P}$ than with the HD seed meter, which is in agreement with studies by Searle et al. (2008), which mention pneumatic seed meters as those that provide the greatest precision in seed distribution.

\section{Flawed spacing between seeds}

Table 8 shows the flawed spacing relating to the interaction between the factors seed meter and conductor tube. It can be observed that T2, T4 and T5 conductors led to an increase in the flawed spacing percentage. This fact may be related to the conductor tube geometry, confirming findings by Mialhe (2012), wherein the author states that tubes carrying seeds to the seeding bed by gravity can be highly harmful in precision seeding, by causing the seeds to rebound in their inside.

When using the $\mathrm{P}$, the form of seed release by the seed meter disc may have been what aggravated the occurrence of flaws in the distribution for T1, T4 and T5 conductors. T3 and $\mathrm{T} 6$ conductors did not differ from each other, and showed the lowest flawed spacing rates. The curvature of the conductor tube combined with adequate internal diameter may have been what led to the low flaw percentage in distribution.

\section{Materials and Methods}

\section{Location}

The experiment was conducted on the premises of the Laboratory of Research and Development of Agricultural Machinery (LASERG), linked to the Federal University of Santa Maria. 
Table 3. Conductive tubes specifications used in tests.

\begin{tabular}{lccccc}
\hline $\mathrm{CT}^{[\mathrm{a}]}$ & $\begin{array}{c}\mathrm{L}^{[\mathrm{b}]} \\
(\mathrm{mm})\end{array}$ & $\mathrm{IA}^{[\mathrm{c}]}($ degrees$)$ & $\begin{array}{c}\mathrm{DA}^{[\mathrm{d}]} \\
(\text { degrees})\end{array}$ & $\begin{array}{c}\mathrm{SI}^{[\mathrm{e}]} \\
(\mathrm{mm})\end{array}$ & $\begin{array}{c}\mathrm{SO}^{[\mathrm{f}]} \\
(\mathrm{mm})\end{array}$ \\
\hline T 1 & 407.40 & 6.93 & 0.00 & $320 \times 430$ & $280 \times 180$ \\
T 2 & 372.20 & 0.00 & 0.00 & 440 & $420 \times 120$ \\
T 3 & 467.20 & 0.00 & 36.56 & $530 \times 350$ & $360 \times 150$ \\
T 4 & 455.50 & 14.15 & 0.00 & $300 \times 400$ & $270 \times 180$ \\
T 5 & 455.90 & 17.71 & 18.74 & $280 \times 540$ & $220 \times 220$ \\
T 6 & 464.90 & 0.00 & 33.98 & $750 \times 510$ & $440 \times 190$ \\
\hline
\end{tabular}

Legend: ${ }^{[a]} \mathrm{CT}=$ Conductive tube; ${ }^{[b]} \mathrm{L}=$ Length; $;{ }^{[\mathrm{d}]} \mathrm{IA}=$ Input angle; $;{ }^{[\mathrm{d}]} \mathrm{DA}=$ Discharge angle; ${ }^{[\mathrm{e}]} \mathrm{SI}=$ Seeds input measures; $;{ }^{[\mathrm{f}]} \mathrm{SO}=$ Seeds output measures.

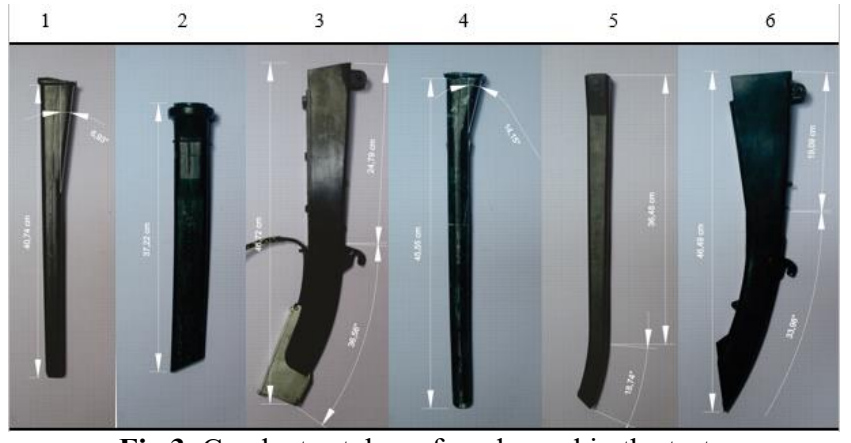

Fig 3. Conductor tubes of seeds used in the tests.

Table 4. Variance analysis results and accuracy and spacing average tests between soybean seeds

\begin{tabular}{|c|c|c|c|c|}
\hline \multirow[t]{2}{*}{ Factors } & \multicolumn{4}{|c|}{ Variables } \\
\hline & Precision (\%) & Acceptable (\%) & Multiple (\%) & Flawed (\%) \\
\hline \multicolumn{5}{|l|}{ F1 seed meter } \\
\hline Horizontal Disc (HD) & $28.12 \mathrm{a}$ & $57.32 \mathrm{~b}$ & $26.43 \mathrm{a}$ & $16.09 \mathrm{a}$ \\
\hline Pneumatic $(\mathrm{P})$ & $26.21 \mathrm{~b}$ & $61.38 \mathrm{a}$ & $23.04 \mathrm{~b}$ & $15.56 \mathrm{a}$ \\
\hline $\mathrm{CV}^{[\mathrm{a}]}(\%)$ & 12.76 & 7.68 & 24.94 & 39.27 \\
\hline \multicolumn{5}{|l|}{ F2 Conductor tube } \\
\hline Conductor 1 (T1) & $27.09 \mathrm{bc}$ & $64.51 \mathrm{~b}$ & $21.48 \mathrm{c}$ & $13.51 \mathrm{~b}$ \\
\hline Conductor 2 (T2) & $27.52 \mathrm{bc}$ & $48.76 \mathrm{c}$ & $30.48 \mathrm{~b}$ & $20.72 \mathrm{a}$ \\
\hline Conductor 3 (T3) & $24.51 \mathrm{~d}$ & $76.27 \mathrm{a}$ & $13.14 \mathrm{~d}$ & $10.58 \mathrm{bc}$ \\
\hline Conductor 4 (T4) & $29.79 \mathrm{a}$ & $44.47 \mathrm{~d}$ & $35.45 \mathrm{a}$ & $20.08 \mathrm{a}$ \\
\hline Conductor 5 (T5) & $28.22 \mathrm{ab}$ & $45.93 \mathrm{~cd}$ & $32.22 \mathrm{ab}$ & $21.85 \mathrm{a}$ \\
\hline Conductor 6 (T6) & $25.87 \mathrm{~cd}$ & $76.15 \mathrm{a}$ & $15.64 \mathrm{~d}$ & $8.20 \mathrm{c}$ \\
\hline CV $(\%)$ & 10.15 & 7.19 & 18.76 & 31.13 \\
\hline \multicolumn{5}{|l|}{ F3Density $\left(\right.$ Seeds ha $\left.{ }^{-1}\right)$} \\
\hline 250.000 & 25.63 & 61.77 & 21.43 & 16.79 \\
\hline 300.000 & 27.39 & 61.27 & 22.20 & 16.17 \\
\hline 350.000 & 25.85 & 55.87 & 27.42 & 16.70 \\
\hline 400.000 & 29.79 & 58.48 & 27.90 & 13.63 \\
\hline CV (\%) & 10.51 & 9.01 & 23.94 & 33.10 \\
\hline \multicolumn{5}{|l|}{ F Test } \\
\hline F1 seed meter & $14.64 * *$ & $38.15 * *$ & $14.46 * *$ & $0.35 \mathrm{~ns}$ \\
\hline F2 Conductive tube & $14.20 * *$ & $389.62 * *$ & $128.19 * *$ & $44.62 * *$ \\
\hline F3 Density & $21.68--$ & $12.53--$ & $15.76--$ & $3.88--$ \\
\hline F1 X F2 & $4.69 * *$ & $34.14 * *$ & $13.77 * *$ & $4.05 * *$ \\
\hline F1 X F3 & $0.13 \mathrm{~ns}$ & $6.67 * *$ & $2.21 \mathrm{~ns}$ & $1.07 \mathrm{~ns}$ \\
\hline F2 X F3 & $0.76 \mathrm{~ns}$ & $1.74 \mathrm{~ns}$ & $0.77 \mathrm{~ns}$ & $0.57 \mathrm{~ns}$ \\
\hline $\mathrm{F} 1 \mathrm{XF} 2 \mathrm{X} F 3$ & $1.00 \mathrm{~ns}$ & $3.99 * *$ & $1.68 \mathrm{~ns}$ & $1.98 \mathrm{~ns}$ \\
\hline
\end{tabular}

Averages followed by the same letter in each column not significantly different at $5 \%$ probability error level through the Tukey test. $* *$ Significant at $0,01 \%$ probability (p $<0.01) *$ significant at $0.05 \%$ probability $(0.01=<\mathrm{p}<0.05)$ ns not significant $(\mathrm{p}>=0.05)$; ${ }^{[\mathrm{a}]} \mathrm{CV}=$ variation coefficient. 
Table 5. Split averages of the seed meter and the conductor tube interaction for the variable precision in soybean seeds.

\begin{tabular}{lll}
\hline \multirow{2}{*}{ Conductor tube } & \multicolumn{2}{c}{ Seed metering mechanism } \\
\cline { 2 - 3 } & $\mathrm{HD}^{[\mathrm{a}]}$ & $\mathrm{P}^{[\mathrm{b}]}$ \\
\hline T1 & $28.24 \mathrm{aAB}$ & $25.95 \mathrm{bBC}$ \\
$\mathrm{T} 2$ & $27.87 \mathrm{aAB}$ & $27.16 \mathrm{aB}$ \\
$\mathrm{T} 3$ & $26.13 \mathrm{aB}$ & $22.89 \mathrm{bD}$ \\
$\mathrm{T} 4$ & $29.41 \mathrm{aA}$ & $30.17 \mathrm{aA}$ \\
T5 & $28.64 \mathrm{aAB}$ & $27.81 \mathrm{aAB}$ \\
T6 & $28.46 \mathrm{aAB}$ & $23.28 \mathrm{bCD}$ \\
\hline
\end{tabular}

Averages followed by the same upper case letter on each line and lower case letter on each column were not significantly different 0.05 probability level by the Tukey test; DMS columns $=2.07$; DMS lines $=2.96 ; \mathrm{HD}^{[\mathrm{a}]}=$ Horizontal Disc $\mathrm{P}^{[\mathrm{b}]}=$ Pneumatic

Table 6. Split averages of acceptable spacing variable between seed meter and seeding density in soybean seeds.

\begin{tabular}{lcccc}
\hline \multirow{2}{*}{ Seed meter } & \multicolumn{4}{c}{ Density (thousand seeds ha ${ }^{-1}$ ) } \\
\cline { 2 - 5 } & 250 & 300 & 350 & 400 \\
$\mathrm{HD}^{[\mathrm{a}]}$ & $56.92 \mathrm{~B}$ & $59.53 \mathrm{~B}$ & $54.48 \mathrm{~A}$ & $58.33 \mathrm{~A}$ \\
$\mathrm{P}^{[\mathrm{b}]}$ & $66.61 \mathrm{~A}$ & $63.02 \mathrm{~A}$ & $57.26 \mathrm{~A}$ & $58.63 \mathrm{~A}$ \\
\hline
\end{tabular}

Averages followed by the same letter in each column were not significantly different. The Tukey test was applied at 0.05 probability level; DMS columns $=2.96{ }^{[a]} \mathrm{HD}=$ Horizontal Disc ${ }^{[b]} \mathrm{P}=$ Pneumatic.
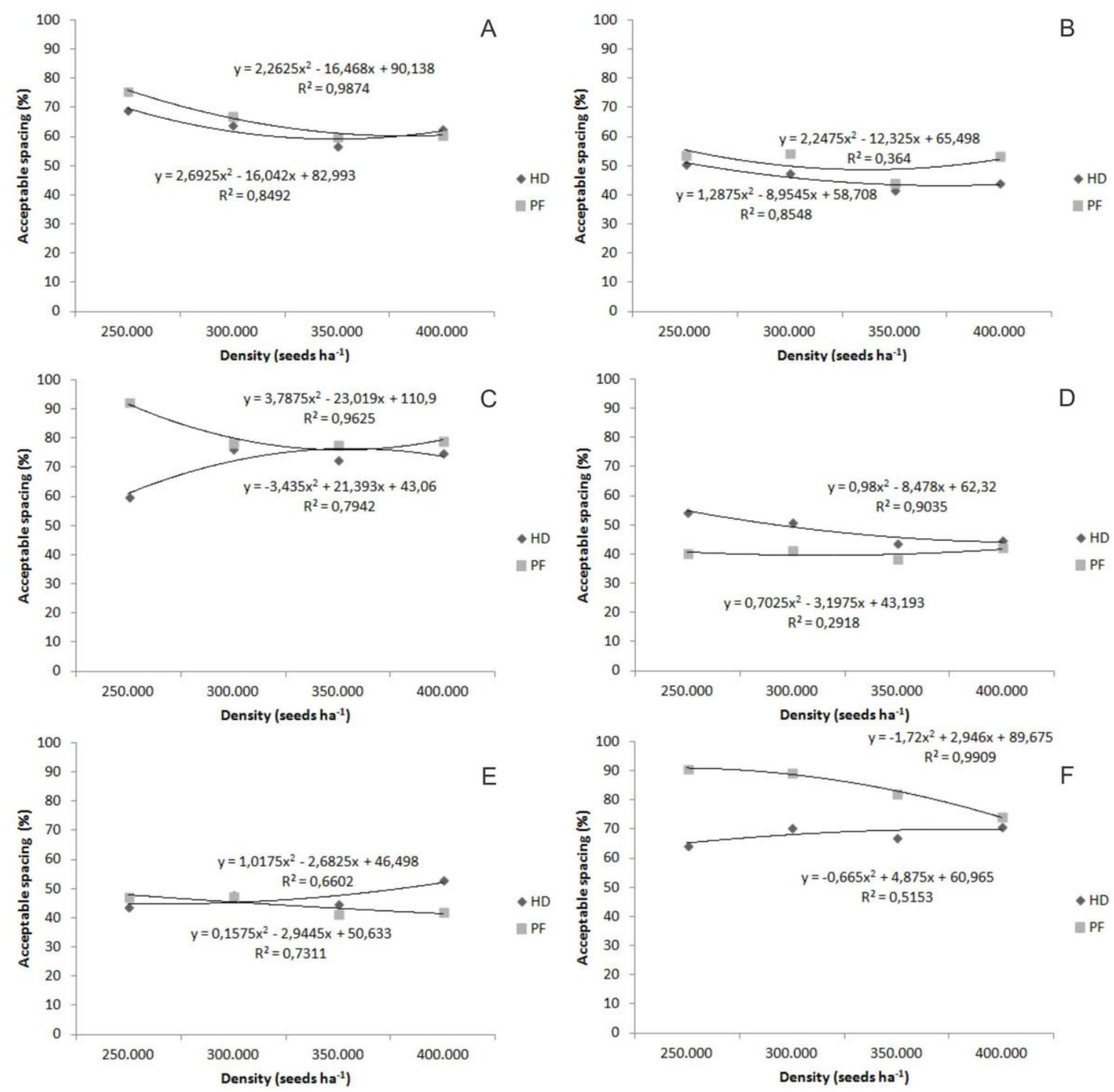

Fig 4. Percentage of acceptable spacing and regression equations for the four seeding densities and increased peripheral speed of the seed meter discs with soybean seeds. P.: Pneumatic seed meter- HD.: horizontal disc seed meter. Conductor tube 1 - Fig A; Conductor tube 2 - Fig B; Conductor tube 3 - Fig C; Conductor tube 4 - Fig D; Conductor tube 5 - Fig E; Conductor tube 6 - Fig F. 
Table 7. Split averages of multiple spacing for seed meter and conductor tubes interaction in soybean seeds.

\begin{tabular}{lcc}
\hline \multirow{2}{*}{ Conductor tube } & \multicolumn{3}{c}{ Seed Metering Mechanism } \\
\cline { 2 - 3 } & $\mathrm{HD}^{[\mathrm{a}]}$ & $\mathrm{P}^{[\mathrm{b}]}$ \\
\hline T1 & $23.90 \mathrm{aB}$ & $19.06 \mathrm{bC}$ \\
T2 & $33.12 \mathrm{aA}$ & $27.84 \mathrm{bB}$ \\
T3 & $17.19 \mathrm{aC}$ & $9.10 \mathrm{bD}$ \\
T4 & $32.15 \mathrm{bA}$ & $38.75 \mathrm{aA}$ \\
T5 & $31.76 \mathrm{aA}$ & $32.69 \mathrm{aB}$ \\
T6 & $20.47 \mathrm{aBC}$ & $10.82 \mathrm{bD}$ \\
\hline
\end{tabular}

Averages followed by the same lower case letter on each line and upper case letter in each column were not significantly different at 0.05 probability level by the Tukey test; DMS columns $=3.54$; DMS lines $=4.98 ;{ }^{[a]} \mathrm{HD}=$ Horizontal Disc $;{ }^{[b]} \mathrm{P}=$ Pneumatic seed meter

Table 8. Split averages of flawed spacing of the seed meter and conductor tubes interaction in soybean seeds.

\begin{tabular}{lcc}
\hline \multirow{2}{*}{ Conductor tube } & \multicolumn{3}{c}{ Seed Metering Mechanism } \\
\cline { 2 - 3 } & $\mathrm{HD}^{[\mathrm{a}]}$ & $\mathrm{P}^{[\mathrm{b}]}$ \\
\hline T1 & $12.03 \mathrm{aB}$ & $15.00 \mathrm{aB}$ \\
T2 & $20.90 \mathrm{aA}$ & $20.54 \mathrm{aA}$ \\
T3 & $12.03 \mathrm{aB}$ & $9.14 \mathrm{aC}$ \\
T4 & $19.37 \mathrm{aA}$ & $20.78 \mathrm{aA}$ \\
T5 & $20.86 \mathrm{aA}$ & $22.85 \mathrm{aA}$ \\
T6 & $11.36 \mathrm{aB}$ & $5.04 \mathrm{bC}$ \\
\hline
\end{tabular}

Averages followed by the same lower case letter on each line and upper case letter on each column were not significantly different at the 0.05 probability level by the Tukey test; DMS columns $=3.70$; DMS lines $=5.29 ;{ }^{[a]} \mathrm{HD}=$ Horizontal Disc $;{ }^{[\mathrm{b}]} \mathrm{P}=$ Pneumatic seed meter.

\section{Materials and Methods}

A seed meter test bench (BEDOSA) was used, developed by the laboratory staff, see fig. 1. A frequency inverter connected to an electric motor was used to change seed disc rotation. Seeds were placed under a felt-coated conveyor belt (see Fig 1), simulating agricultural soil, measuring $17.5 \mathrm{~m}$ long by $0.15 \mathrm{~m}$ wide. The conveyor belt and the seed metering discs are also activated by a three phase electric motor with asynchronous induction of $2208 \mathrm{~W}(3 \mathrm{CV})$, driven by a CFW08 frequency inverter with single-phase input 200-240 $\mathrm{V}$.

The vertical disc pneumatic seed meter used was the Precision Planting model, which uses the negative pressure of the air as a means of separation and retention of seeds (Fig 2) Pressure control was achieved through a vacuum gauge which set the required pressure recommended by the meter manufacturer. A STARA horizontal disc meter was also used (Fig 2).

\section{Plant material}

The soybean (Glycine max) seeds used were Syngenta NK 7059 RR, 6.5 sieve. The main dimensional features of the seeds are in Table 1, and they were determined on samples consisting of 50 seeds with the aid of a digital caliper.

The sphericity was calculated by the following equation:

$\phi=\frac{(L W T)^{1 / 3}}{L} \times 100$

Where:

$\emptyset=$ sphericity, $\%$;

$\mathrm{L}=$ length (mm)

$\mathrm{W}=$ width $(\mathrm{mm})$

$\mathrm{T}=$ thickness $(\mathrm{mm})$

The percentage precision obtained by seed meters was calculated by the following equation:

$\% P=(S D /$ Xref $) \times 100$

Where:

$\% \mathrm{P}=$ Percentage precision

$\mathrm{SD}=$ Standard deviation

Xref $=$ Theoretical spacing of each crop
Four seeding densities were used, 250, 300, 350 and 400 thousand seeds per hectare, resulting from four seed meter disc rotations for the same simulated ground speed, simulating a seeding operation for precision agriculture with a row spacing of $0.45 \mathrm{~m}$. The conveyor belt speed, which simulated seeder movement, was kept at $1.67 \mathrm{~m} \mathrm{~s}^{-1}$ and only the peripheral speeds of the meter discs were changed. The established speed is intermediate to the speed recommended by ISO 7256/1 standard, which cites speeds of 1.39 and 1.94 $\mathrm{m} \mathrm{s}^{-1}$. During testing, the bench with the seed meters remained leveled longitudinally and transversally, and the seed boxes of the seed were kept full. The manual spacing count was performed using of a tape measure, extended parallel to the conveyor belt, the data were entered into spreadsheets, where the spacings were then classified as per ISO 7256/1 (1982) and also ABNT (1994), standards, which classify spacing as: acceptable $\left(0,5 \mathrm{X}_{\text {ref. }}<\mathrm{X}_{\mathrm{i}}<1,5 \mathrm{X}_{\text {ref }}\right)$, multiple $\left(X_{i}<0,5 X_{\text {ref. }}\right)$ and flawed $\left(X_{i}>1,5 X_{\text {ref. }}\right)$, where $X_{\text {ref. }}$ corresponds to the theoretical spacing of each crop. 158 spacings were observed, the specifications of the conductor tubes used (figure 5) are shown in Table 3.

\section{Treatments and statistical analysis}

The experimental design was a randomized block in subdivided parcels, with $2 \times 6 \times 4$ factorial arrangement with four repetitions, totaling 182 experiment units. The first factor was composed of two seed metering mechanisms, pneumatic and horizontal disc meter; the second factor, consisted of six conductor tubes, and the third factor, seeding density rate in four levels. The averages of the data for acceptable, multiple and flawed spacing collected were submitted to variance analysis (ANOVA). When factors significance was found by the $\mathrm{F}$ test, the averages were submitted to the Tukey test at $0.05 \%$ error probability to detect differences among them. The analyzes were performed using Assistat software, 7.6 beta version (Silva and Azevedo, 2002).

\section{Conclusions}

With the increase in seeding density and, consequently, the peripheral speed of the metering disc, there was a tendency 
towards the reduction of acceptable spacing for most conductors. The pneumatic $(\mathrm{P})$ vertical disc meter had better seed distribution quality than the horizontal disc meter (HD). Straight and small diameter tubes (conductors T2, T4 and T5) showed the worst quality in seed distribution, while conductor tubes with a parabolic profile and an exit angle close to 30 degrees (conductors T3 and T6), presented the best performance in relation to longitudinal seed distribution, regardless of the type of seed metering disc used.

\section{Acknowledgements}

Coordenação de Aperfeiçoamento de Pessoal (CAPES) by the Financial support provided and STARA S. A. Industry of Agricultural Implements

\section{References}

ABNT (1994) Brazilian Association of Technical Standards. Standard Project 04:015:06-004. Precision seeder: laboratory test. Rio de Janeiro, RJ, p 7.

Bainer R, Kepner, RA, Barger EL (1963) Principles of farm machinery, 3rd edn. Wiley, New York.

Bernacki H, Haman I, Kanafojski CZ (1984) Travel Speed effect on operational characteristics of seeders. Ed. $\mathrm{n}^{\mathrm{o}} 1$ (97). Campinas, SP. Agricultural Machines Theory and Construction. Agronomic Institute of Campinas. 97: p 13.

Coelho JLD (1996) Testing \& certification tips machines for sowing. In MIALHE LG. Used farm equipment: testing \& certification. Piracicaba: of Agrarian Studies Foundation Luiz de Queiroz, 551-569.

Dias V de O, Alonço A dos S, Baumhardt UB, Bonotto GJ (2009) Distribution of maize and soybean seeds as a function of speed and seeding density. Cienc Rural, 39. (6): 1721-1728.

Futral JG, Allen RJ (1951) Development of a high speed planter. Agric Eng, St Joseph, MI 32 (4): 215-216.

Heiffig L S (2006) Closing and leaf area index of soybean at different spatial arrangements. Bragantia. 65 (2): 285-295.

ISO (1982) International Organization for Standardization. ISO: 7256/1: Sowing equipment - methods of test: part 1 . Single seed drills (precision drills). Geneva, p 16.

Jasper R, Janszen U, Jasper M, Garcia Luiz C (2006) Longitudinal distribution and corn seed germination with the use of phytosanitary treatment and graphite. Eng Agric. 26(1): 292-299.

Kachman SD, Smith JA (1995) Alternative measures of accuracy in plant spacing for planters using single seed metering. T ASAE. 38(2): 379-387.

Kocher MF, Coleman JM, Smith JA, Kachman SD (2011) Corn seed spacing uniformity as affected by seed tube condition. Appl Eng Agric. 27(2):177-183.
Searle CL, Kocher MF, Smith JA, Blankenship EE (2008) Field slope effects on uniformity of corn seed spacing for three precision planter metering systems. Appl Eng Agric. 24(5): 581-586.

Mialhe LG (2012) Máquinas agrícolas para plantio: Millennium (ed) 1rd edn. Campinas, São Paulo.

Oliveira AC, Vieira LB, Mantovani EC, De Souza MC, Dias GP (2000) Performance of a seeder for direct seeding in two soils with different types of vegetation. Brazil Agric Res. 35(7): 1455-1463.

Reis EF, Moura JR, Delmond JG, Cunha JPAR (2007) Operational characteristics of a no-till seeder in soybean (Glycine Max (L.) Merril). Tech Agric Sci. 16(3): 70-75.

Silva F de AS, Azevedo CAV de (2002) Assistat version of the computer program for the operating system Windows. J Agroindustrial Products. 4(1): 71-78.

Silva JG, Kluthcouski J, Silveira PM (2000) Performance of a planter in establishing and productivity of corn under notillage. Sci Agric, Piracicaba. 57 (1): 7-12.

Tourino MCC, Daniel LA (1996) Soybean distribution uniformity Evaluation [Glycine $\max (\mathrm{L}$.$) Merril]. Cienc$ Agrotec. 20(2): 238-244

Wanjura DF, Hudspeth Junior EB (1968) Metering seedpattern characteristics of a horizontal edge-drop plate planter. T ASABE. 11 (4): 468-469 